\title{
A study on heat release rate indicator in the auto-igniting droplets using direct numerical simulation
}

\author{
Jing $\mathrm{CHEN}^{*}$ and Yiliang CHEN* \\ *Department of Thermal Science and Energy Engineering \\ University of Science and Technology of China \\ Jinzhai Road \#96, Hefei, Anhui, 230027,P.R.China \\ E-mail: chenjing0613@gmail.com
}

Received 3 December 2015

\begin{abstract}
Local heat release rate is one of the most concerned parameters in the combustion processes. However, this parameter is hard to be measured directly in the experiments. Therefore local heat release rate indicators have been sought and evaluated, and many works focus on the study in the gaseous laminar or turbulent premixed flames. The motivation of this work is to explore and validate heat release rate indicators for auto-igniting n-heptane droplets. To this end, direct numerical simulation (DNS) is performed with a detailed chemical reacting mechanism. Results show that the product of mass fractions of $\mathrm{OH}$ and $\mathrm{CH}_{2} \mathrm{O}$ is a proper indicator when the local auto-ignition prevails and the temperature rises quickly. The elementary reactions involved are analyzed, which shed light on the construction and performance of heat release rate indicators. Some new definitions of the indicators are proposed and evaluated. The proportional relationship between the indicator and the actual local heat release rate is determined. The heat release associated with different combustion regimes are distinguished, which reveals the dominant role of premixed flames in the droplets auto-ignition processes.
\end{abstract}

Key words : Heat release rate indicator, Direct numerical simulation, Auto-ignition, Liquid droplets

\section{Introduction}

The local heat release rate is an important parameter in combustion process and is deeply concerned by the combustion researchers. For example, in the study of the auto-ignition phenomenon, present of reacting kernels containing some free radicals like $\mathrm{CH}_{2} \mathrm{O}$ (HCHO) is recognized (Aggarwal 1998; Mastorakos 2009; Jenny et al. 2012) . Heat release rate in these kernel structures was emphasized to shed light on the ignition mechanism(Gordon et al. 2009). Meanwhile, the local heat release rate is also of vital significance in many industrial applications. However, this parameter is difficult to be measured directly in experiments. The experimental researchers made use of the concentrations of specific species as the heat release rate indicator (HRI) to represent the magnitude of heat release rate. Some examples of reported HRIs are $\mathrm{OH}$ or $\mathrm{CH}$ radical chemiluminescence (Kathrotia et al. 2009), product of mass fraction of $\mathrm{OH}$ and $\mathrm{CH}_{2} \mathrm{O}$ (Paul and Najm 1998; Dworkin et al. 2009) and product of mass fractions of $\mathrm{OH}$ and CO (Rehm and Paul 2000; Frank et al. 2002; Amantini et al. 2007).

The product of $\mathrm{OH}$ and $\mathrm{CH}_{2} \mathrm{O}$ by simultaneous LIF images was firstly reported by Paul and Najm (1998) as a good indicator for laminar flames. It was also adopted in the study of the lean premixed turbulent flames (Balachandran et al. 2005). By comparing the product of $\mathrm{OH}$ and $\mathrm{CH}_{2} \mathrm{O}$ with the $\mathrm{OH}$ chemiluminescence, Ayoola et al. (2006) found that the former HRI can further be used to study the effect of strain rates on the local heat release. This kind of indicator is inspired by the flame-front indicator in premixed flames (Paul and Najm 1998) and shows some consistency with the elementary reactions $\left(\mathrm{CH}_{2} \mathrm{O}+\mathrm{OH} \Leftrightarrow \mathrm{HCO}+\mathrm{H}_{2} \mathrm{O}\right.$ and $\left.\mathrm{CO}+\mathrm{OH} \Leftrightarrow \mathrm{CO}_{2}+\mathrm{H}\right)$. Its validity in the laminar flames and gaseous premixed flames is extensively evaluated (Rehm and Paul 2000; Frank et al. 2002; Fayoux et al. 2005; Amantini et al. 2007). The proposed HRIs have been used in many turbulent studies. For example, Gordon et al. (2009) 
and O'Loughlin et al. (2012) used the product of $\mathrm{OH}$ and $\mathrm{CH}_{2} \mathrm{O}$ to represent the heat release rate at the base of a turbulent lifted methane flame and the methanol flame in the investigations of stabilization mechanisms. Meanwhile, new heat release indicators are also proposed in the study of the laminar premixed flames recently. The elementary reaction $\mathrm{CH}_{2} \mathrm{O}+\mathrm{OH} \Leftrightarrow \mathrm{HCO}+\mathrm{H}_{2} \mathrm{O}$ is re-examined in the multi-component fuel flame in the reference (Nikolaou et al. 2014) and the alternative indicators are proposed and evaluated. Mulla et al. (2016) experimentally evaluated the product of $\mathrm{H}$-atom and $\mathrm{CH}_{2} \mathrm{O}$ in the laminar premixed flames.

Currently, most of the reported HRIs are for gaseous laminar and turbulent premixed flames. Their validity and performance in the two-phase combustion or in higher hydrocarbons flames need be evaluated. More importantly, the mechanism of what makes it a proper HRI or how to find a good HRI has not been investigated systematically. The quantitative relationship between the indicator and the actual local heat release rate is not yet determined in the turbulent studies. This paper aims to make a contribution to the above issues by numerical simulation. Direct numerical simulation (DNS) is performed to study the HRIs for the auto-igniting n-heptane droplets distributed in the hot vitiated flow.

DNS is believed to resolve the turbulence completely, and it has been extended to the study of two-phase combustion. Auto-ignition of the liquid droplets in hot circumstance is one interested topic of DNS (Baba and Kurose 2008; Fujita et al. 2013; Kitano et al. 2013). The specific methods include two dimensional (2D) DNS coupled with the detailed reacting mechanism (Wang and Rutland 2007; Yoo et al. 2009; Wang and Rutland 2005) and 3D DNS coupled with the simplified reacting mechanism (Wang et al. 2012; Schroll et al. 2009; Wang et al. 2014). The effects of the relevant parameters, e.g. the overall equivalence ratio, the droplet diameter and its distribution, the initial gas temperature, pressure on ignition delay time were examined (Wang and Rutland 2005, 2007; Im et al. 1998). So far, 3D DNS coupled with the detailed reacting mechanism (Borghesi et al. 2013) is rare due to huge requirement of calculation resources. Meanwhile, DNS also favors to the optimization of the related models in gaseous or two-phase combustion simulation. For instance, the droplets evaporation model coupled with the detailed chemical reacting mechanism is a concerned issue. Recently, Kitano et al. (2014 a, 2014 b) used 3D DNS to investigate the multi component fuel droplets evaporation model and to deepen the understanding of the evaporation and combustion interaction. It is clear that for the present study of HRI for auto-igniting n-heptane droplets, DNS is a powerful tool and that the simplified mechanism is not adequate.

In present paper, 3D DNS is performed with a detailed chemical reacting mechanism to calculate the auto-ignition process of $n$-heptane droplets in homogeneous isotropic turbulence (HIT). The paper examines the validity of the reported HRIs, such as the product of $\mathrm{OH}$ and $\mathrm{CH}_{2} \mathrm{O}, \mathrm{OH}$ and $\mathrm{CO}$. The contours of instantaneous distribution, the value of the linear correlation coefficients and the goodness of fit are used to evaluate the performance of different HRIs qualitatively and quantitatively. The elementary reactions involved are analyzed to find the features of good HRIs, which shed light on the criteria and guidelines to construct new HRIs for different combustion process. The relationship between the indicator and the actual local heat release rate are determined. In addition, the effects of some relevant properties, such as combustion regime and turbulence intensity, are examined.

\section{Nomenclature}

$\begin{array}{llll}D_{t} & \text { individual derivative operator } & \rho & \text { gaseous mixture density } \\ p & \text { gaseous pressure } & \mu & \text { gaseous viscosity } \\ u_{i} & i \text {-th component of gaseous velocity } & \alpha & \text { gaseous thermal diffusivity } \\ D_{i} & i \text {-th species diffusivity } & H & \text { total enthalpy } \\ \dot{w}_{i} & \text { chemical source term } & m_{d} & \text { droplet's mass } \\ u_{d} & \text { droplet's velocity } & T_{d} & \text { droplet's temperature } \\ c_{p, l} & \text { droplet's specific heat } & \Delta V & \text { Euler control volume } \\ h_{i} & i \text {-th species formation enthalpy } & x_{d} & \text { droplet's position } \\ T_{g} & \text { gaseous temperature } & c_{p, g} & \text { gaseous specific heat }\end{array}$




\begin{tabular}{|c|c|c|c|}
\hline$\tau_{d}$ & droplet's respond time & $\operatorname{Pr}$ & Prandtl number \\
\hline$S c$ & Schmidt number & $N u$ & Nusselt number \\
\hline$S h$ & Sherwood number & $\operatorname{Re}_{s l}$ & droplet's Reynolds number \\
\hline$u_{s l}$ & Slip velocity & $B_{M}$ & Spalding number \\
\hline$Y_{v, s}$ & fuel vapor mass fraction at interface & $\beta$ & evaporation parameter \\
\hline$L_{v}$ & latent heat of evaporation & $\chi_{s, e q}$ & $\begin{array}{l}\text { surface equilibrium mole fraction } \\
\text { of the vapor }\end{array}$ \\
\hline $\mathrm{W}_{c}$ & gaseous molecular weight & $\mathrm{W}_{v}$ & droplet molecular weight \\
\hline$T_{b}$ & liquid boiling temperature & $\bar{R}$ & universal gas constant \\
\hline$n$ & number of droplets & $\Delta t$ & gaseous time step \\
\hline$\Delta t_{d}$ & liquid phase time step & $\tau_{m}$ & evaporation time scale \\
\hline$\tau_{h}$ & heat transfer time scale & $L$ & side length of the box \\
\hline$k$ & wave number & $k_{\eta}$ & Kolmogorov wave number \\
\hline $\bar{k}$ & total turbulence kinetic energy & $\eta$ & Kolmogorov length scale \\
\hline$\Delta x$ & the grid minimum scale & $d$ & initial droplet's diameter \\
\hline$\varphi$ & overall equivalence ratio & $\tau_{\eta}$ & Kolmogorov time scale \\
\hline$L_{11}$ & the integral length scale & $\operatorname{Re}_{t}$ & Taylor Reynolds number \\
\hline$t$ & time & $F I$ & the flame index \\
\hline$\chi$ & scalar dissipation rate & $Z$ & mixture fraction \\
\hline$H R$ & heat release rate & HRavg & volume averaged $H R$ \\
\hline$s$ & linear slope & dis & linear intercept \\
\hline$Y_{f}$ & fuel mass fraction & $Y o$ & oxidizer mass fraction \\
\hline$H R I$ & heat release rate indicator & $R^{2}$ & coefficient of determination \\
\hline$Z_{\text {turn }}$ & turning value of $\mathrm{Z}$ & & \\
\hline
\end{tabular}

\section{Computational Methods}

\subsection{Gas phase conservation equations}

As to the gas-phase, the mass equation, the Navier-Stokes equations, the species equations and the energy equation in the incompressible case are as follows

$$
\begin{aligned}
& D_{t} \rho=S_{m} \\
& D_{t}\left(\rho u_{i}\right)=-\nabla p+\nabla \cdot\left(\mu \nabla u_{i}\right)+S_{i} \\
& D_{t}\left(\rho Y_{i}\right)=\nabla \cdot\left(\rho D_{i} \nabla Y_{i}\right)+\dot{w}_{i}+S_{Y i} \\
& D_{t}(\rho H)=\nabla \cdot(\rho \alpha \nabla H)+S_{H}
\end{aligned}
$$

Unity Lewis number is adopted in the simulation. The chemical source terms $\dot{w}_{i}$ in the species equations are calculated by integration of the detailed chemistry mechanism using the DVODE solver. In present study a chemical reacting mechanism (Liu et al. 2004) with 44 species 112 element reactions is adopted and all the 44 species transport equations are solved. The local heat release rate due to the chemical reactions is calculated by 


$$
H R=\sum \dot{w}_{i} h_{i}
$$

where $h_{i}$ is the formation enthalpy of each species and the unit of the heat release rate is $\mathrm{J} /\left(\mathrm{m}^{3} \mathrm{~s}\right)$.

\subsection{Liquid phase conservation equations}

Interior motions and rotation of the droplets, droplet-droplet interaction and coalescence are all neglected since present simulation focuses on the dilute spray. DNS here implies a complete resolution of the gas phase on scales equal to and larger than the Kolmogorov length scales and timescale. While for the liquid phase, the spatial scale is too small to reach in present DNS, and the use of numerical models is inevitable. The droplets are tracked in the Lagrangian framework, and the governing equations for an individual spherically symmetric droplet are

$$
\begin{aligned}
\frac{d x_{d, i}}{d t} & =u_{d, i} \\
\frac{d u_{d, i}}{d t} & =\frac{f_{1}}{\tau_{d}}\left(u_{i}-u_{d, i}\right) \\
\frac{d T_{d}}{d t} & =\frac{N u}{3 \operatorname{Pr}}\left(\frac{f_{2}}{\tau_{d}}\right)\left(\frac{c_{p, g}}{c_{p, l}}\right)\left(T-T_{d}\right)+\frac{L_{v}}{c_{p, l}} \frac{\dot{m}_{d}}{m_{d}} \\
\frac{d m_{d}}{d t} & =-\frac{m_{d}}{\tau_{d}}\left(\frac{S h}{3 S c}\right) \ln \left(1+B_{M}\right)
\end{aligned}
$$

Droplet's response time scale is $\tau_{d}=\rho_{d} d_{d}^{2} /(18 \mu)$. Prandtl number $\operatorname{Pr}=\mu c_{p, g} / \lambda_{g}$ and Schmidt number $S c=\mu_{g} / \rho_{g} \Gamma_{V}$ are set to be 0.7 . The drag force is determined by the local 'slip velocity' $u_{s l, i}=u_{i}-u_{d, i}$. Gravity is neglected. The function $f_{1}$ is empirically corrected for droplet Reynolds numbers (Miller et al. 1998):

$$
\begin{aligned}
& f_{1}=\frac{1+0.0545 \mathrm{Re}_{s l}+0.1 \mathrm{Re}_{s l}^{1 / 2}\left(1-0.03 \mathrm{Re}_{s l}\right)}{1+a\left|\operatorname{Re}_{b}\right|^{b}} \\
& a=0.09+0.077 \exp \left(-0.4 \operatorname{Re}_{s l}\right) \\
& b=0.4+0.77 \exp \left(-0.04 \operatorname{Re}_{s l}\right)
\end{aligned}
$$

where $\operatorname{Re}_{s l}=\rho_{g} u_{s l} d_{d} / \mu$ is based on the slip velocity, $\operatorname{Re}_{b}=\rho_{g} u_{b} d_{d} / \mu$ is based on the blowing velocity $u_{b}$ which can be obtained from the mass conservation relation at the droplet surface $\dot{m}_{d}=-\pi \rho_{g} d_{d}^{2} u_{b}$. Nusselt number $\mathrm{Nu}$ and the Sherwood number $\mathrm{Sh}$ are calculated based on the Ranz-Marshall relationship:

$$
\begin{aligned}
& N u=2+0.552 \operatorname{Re}_{s l}^{1 / 2} \operatorname{Pr}^{1 / 3} \\
& S h=2+0.552 \operatorname{Re}_{s l}^{1 / 2} S c^{1 / 3}
\end{aligned}
$$

The function $f_{2}=\beta /\left(\mathrm{e}^{\beta}-1\right)$ represents a correlation for the convective heat transfer. The non-dimensional evaporation parameter $(\beta)$ is:

$$
\beta=-\left(\frac{3 \operatorname{Pr} \tau_{d}}{2}\right) \frac{\dot{m}_{d}}{m_{d}}
$$


The Spalding number here is based on the mass transfer and is given as:

$$
B_{M}=\left(Y_{v, s}-Y_{v}\right) /\left(1-Y_{v, s}\right)
$$

where $Y_{v, s}$ is the fuel vapor mass fraction at the droplet interface and can be calculated using the equilibrium assumption:

$$
Y_{v, s}=\frac{\chi_{s, e q}}{\chi_{s, e q}+\left(1-\chi_{s, e q}\right)\left(\mathrm{W}_{c} / \mathrm{W}_{v}\right)}
$$

where $\mathrm{W}_{c}$ and $\mathrm{W}_{v}$ are the molecular weight of the carrier gas and the vapor. $\chi_{s, e q}$ is the surface equilibrium mole fraction of the vapor which obeys the Clausius-Clapeyron relation:

$$
\chi_{s, e q}=\exp \left(\frac{L_{v}}{\bar{R} / W_{v}}\left(\frac{1}{T_{b}}-\frac{1}{T_{d}}\right)\right)
$$

where $T_{b}$ is the liquid boiling temperature and $\bar{R}$ is the universal gas constant.

\subsection{Phase coupling terms}

The source terms in Eqs. (1-4) due to liquid droplets are:

$$
\begin{aligned}
& S_{m}=-\frac{1}{\Delta V} \sum_{n} \frac{d m_{d}}{d t} \\
& S_{i}=-\frac{1}{\Delta V} \sum_{n} \frac{d\left(m_{d} u_{d, i}\right)}{d t} \\
& S_{H}=-\frac{1}{\Delta V} \sum_{n}\left[\frac{1}{2} \frac{d\left(m_{d} u_{i} u_{i}\right)}{d t}+\frac{d\left(\mathrm{c}_{p, l} m_{d} T_{d}\right)}{d t}\right] \\
& S_{Y i}=-\frac{1}{\Delta V} \sum_{n} \frac{d m_{d}}{d t} \quad(\mathrm{i}=\text { fuel })
\end{aligned}
$$

where $\Delta V$ is the Euler control volume in which the droplet locates, $n$ is the number of droplets within the control volume, and $\sum$ means the summation of all the droplet in one Euler control volume.

\subsection{Computational setup}

Equations (1-4) are solved using a finite difference scheme and the SIMPLE algorithm is used to deal with the pressure-velocity coupling. The momentum equations are discretized using an eighth-order energy conserving scheme while the scalar equations are discretized using the 3rd WENO scheme to ensure the boundness of the scalars. Temporal discretization is implemented using the second-order semi-implicit Crank-Nicolson scheme. The discretized equations are solved using Newton-Raphson iteration. The periodic boundary condition is adopted in three directions.

In the liquid phase, the discretized Eqs. (6-9) are advanced temporally using the second-order Runge-Kutta scheme, and the time step of liquid phase is determined as follows:

$$
\Delta t_{d}=\min \left(\Delta t, \tau_{d}, \tau_{m}, \tau_{h}\right) / N_{s u b}
$$

where $\Delta t$ is the gaseous time step, $\tau_{m}=m_{d} / \dot{m}_{d}$ is the time scale of evaporation, and

$$
\tau_{h}=\frac{3 \operatorname{Pr} c_{p} \tau_{d}}{N u c_{p, g} f_{2}} \cdot \frac{T_{b}-T_{d}}{T-T_{d}}
$$


is the time scale of heat transfer. $N_{\text {sub }}$ is set to 3 .

The computational domain is a periodic box (as shown in Fig.1) with the homogeneous isotropic turbulence (HIT), and the n-heptane droplets are randomly distributed along three directions. The side length is $5 \mathrm{~mm}$ while a uniform $128^{3}$ grid is used to discretize the domain. This grid scale is in the same order as DNS in References (Borghesi et al. 2013; Wang et al. 2012; Schroll et al. 2009; Wang et al. 2014) and the Kolmogorov scale (shown in Table 1) is able to reach. The initial velocity spectrum prescribed is of the von Karman-Pao form:

$$
\begin{aligned}
& E(k)=\alpha \frac{2 / 3 \bar{k}}{k_{e}} \frac{k / k_{e}}{\left[1+\left(k / k_{e}\right)^{2}\right]^{17 / 6}} e^{\left[-2\left(k / k_{\eta}\right)^{2}\right]} \\
& \bar{k}=\int_{0}^{\infty} E(k) d k
\end{aligned}
$$

where $\alpha=1.45276$ is the Kolmogorov constant, $\bar{k}$ total turbulence kinetic energy, $k_{\eta}$ the Kolmogorov wave number. The parameter $k_{e}$ determines the shape of the energy spectrum and is given by the turbulence energetic scale $L$ :

$$
k_{e}=\frac{2 \pi}{L}
$$

Fig. 1 Sketch of the computational domain.

A background fluctuating velocity field with an R.M.S. of $3 \mathrm{~m} / \mathrm{s}$ is prescribed. Instead of hot air with high pressure as the oxidizer (Borghesi et al. 2013; Mittal et al. 2012; Kitano et al. 2013) in internal combustion engines, hot products of lean premixed hydrogen/air combustion at ordinary pressure (1 atm) are selected as the oxidizer here(O'Loughlin and Masri 2011, 2012). Main species in this oxidizer are $\mathrm{N}_{2} / \mathrm{H}_{2} \mathrm{O} / \mathrm{O}_{2}(0.73: 0.15: 0.12$ by volume). The initial gaseous temperature is $1300 \mathrm{~K}$ and initial droplets temperature is $300 \mathrm{~K}$. The overall equivalence ratio retains at $\varphi=1.0$ with initially all fuel in the liquid phase. Two cases are taken into consideration with different initial droplets diameter as shown in Table 1 . The initial diameter is $20 \mu \mathrm{m}$ in $\mathrm{C} 1$ case and $12 \mu \mathrm{m}$ in $\mathrm{C} 2$ case. The initial diameter is in the same magnitude with the droplets SMD diameter $(40 \mu \mathrm{m})$ in the experiment (O'Loughlin, 2012) in which the droplets are achieved from an ultrasonic generator (Sonotek). The initial diameter is a little larger than that in the reference (Wang et al. 2014). In present work, initial diameter smaller than $8 \mu \mathrm{m}$ leads to the fact that the liquid fuel has all evaporated before the ignition prevails. In this situation, the case is very close to the gaseous ignition and is not focused on by present paper. On the other hand, the initial diameter can not be set too large since in this situation the interior motions, rotation of the droplets and other interactions can not be neglected. The initial gaseous turbulent Reynolds number are configured according to the requirement of calculation resources. If the initial turbulent Reynolds number is larger, the current mesh should be refined to make the grid scale reach the Kolmogorov scale. As shown in Table 1, the grid scale $\Delta x=39 \mu \mathrm{m}$ is smaller than the Kolmogorov scale $\eta$. The comparison of the grid scale with the instantaneous flame structures shows that current mesh is able to capture the fine structures in this combustion field. The time step is dynamically adjusted to ensure $\mathrm{CFL}=0.5$ and the typical value of the time step is $0.3 \mu \mathrm{s}$.

Table 1 List of parameters for the initial DNS field in different cases 


\begin{tabular}{c|c|c|c|c|c|c|c|c|c|c}
\hline \hline & $d[\mu \mathrm{m}]$ & $\varphi$ & $N$ & $T[\mathrm{~K}]$ & $\mathrm{Re}_{t}$ & $\mathrm{Re}_{\lambda}$ & $\eta[\mu \mathrm{m}]$ & $\tau_{\eta}[\mu \mathrm{s}]$ & $\tau_{\text {eddy }}[\mathrm{ms}]$ & $L_{11}[\mathrm{~mm}]$ \\
\hline $\mathrm{C} 1$ & 20 & 1.0 & 426 & 1300 & 438 & 81 & 56 & 86 & 2.7 & 1.9 \\
\hline $\mathrm{C} 2$ & 12 & 1.0 & 1972 & 1300 & 438 & 81 & 56 & 86 & 2.7 & 1.9 \\
\hline
\end{tabular}

\section{Results and Discussion}

\subsection{Transient auto-ignition process}

Evolution of the combustion field is briefly shown in this section to clarify the features of this auto-ignition. The volume averaged temperature and the volume averaged heat release rate (HRavg) in the two cases are displayed in Fig. 2a and Fig.2b. Evolution of the averaged parameters can be divided into three stages roughly. At the early stage, the temperature decreases slightly due to the liquid evaporation and the volume averaged heat release rate remains negligible. The temperature starts rising fast due to the ignition of the evaporated fuel from about $0.25 \mathrm{~ms}$ in $\mathrm{C} 1$ case (or $0.18 \mathrm{~ms}$ in C2 case). Some features of this 'temperature rising' stage can be visualized by the scatter plots of temperature against mixture fraction or its scalar dissipation rate in Fig. 3. It is obvious that auto-ignition occurs at the very lean side with small mixture fraction value and is associated with low scalar dissipation rate as Schroll et al. (2009). The volume averaged heat release rate also rises quickly at this stage and reaches the maximum value at $0.42 \mathrm{~ms}$ in $\mathrm{C} 1$ case (or $0.32 \mathrm{~ms}$ in $\mathrm{C} 2$ case). After this stage the temperature increases slowly indicating the fully development of this flame. The last stage can be called 'fully development' stage and is separated with the 'temperature rising' stage at about $0.5 \mathrm{~ms}$ in $\mathrm{C} 1$ case (or $0.45 \mathrm{~ms}$ in $\mathrm{C} 2$ case). The volume averaged heat release rate goes on declining in this stage. Meanwhile, the comparison of Fig.2a and Fig.2b shows the effect of the droplets diameter on the auto-ignition. The case with smaller droplets ignites earlier, about $0.07 \sim 0.1 \mathrm{~ms}$ in present work. In addition, the final gaseous temperature and the maximum HRavg is higher in $\mathrm{C} 2$ case which is related to the faster droplets evaporation at the early stage. The following instantaneous analysis is mainly based on the $\mathrm{C} 1$ case.

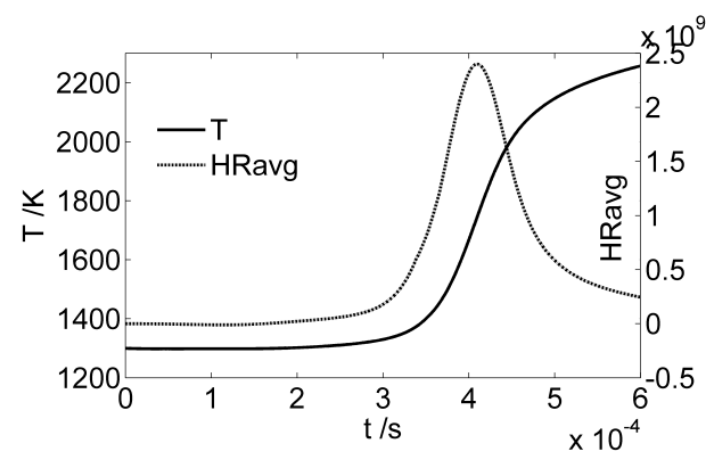

a) Volume averaged parameters in $\mathrm{C} 1$ case

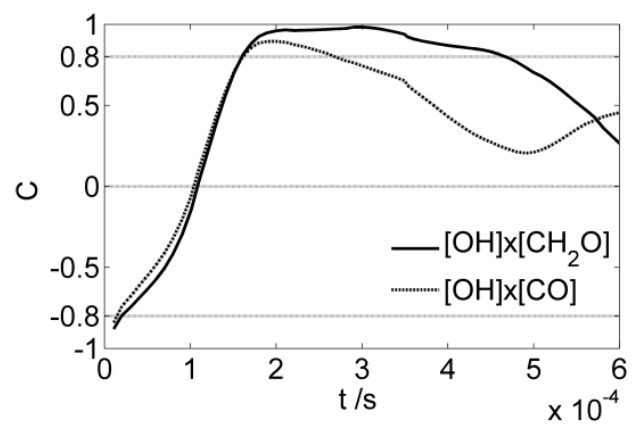

c) Linear correlation coefficients in $\mathrm{C} 1$ case

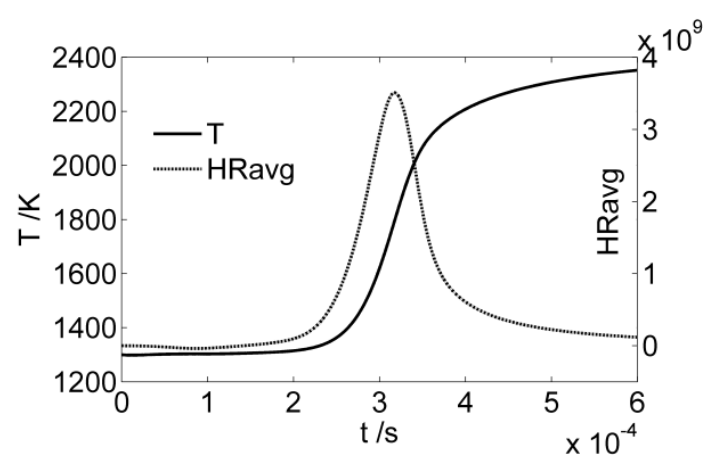

b) Volume averaged parameters in $\mathrm{C} 2$ case

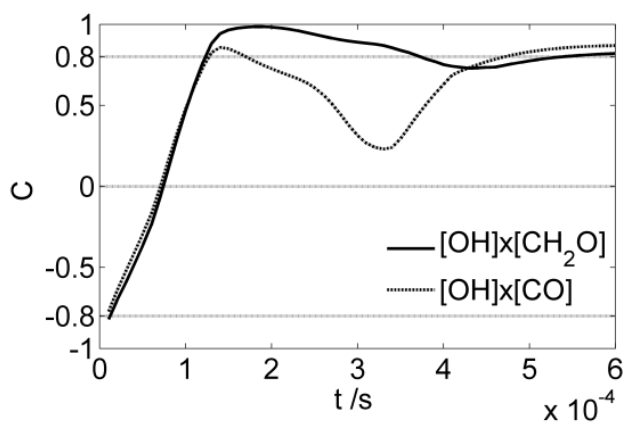

d) Linear correlation coefficients in $\mathrm{C} 2$ case

Fig. 2 Volume averaged temperature ( $T$, solid line) and heat release rate (HRavg, dashed line) against time (a, b), and linear correlation coefficients against time $(c, d)$. 


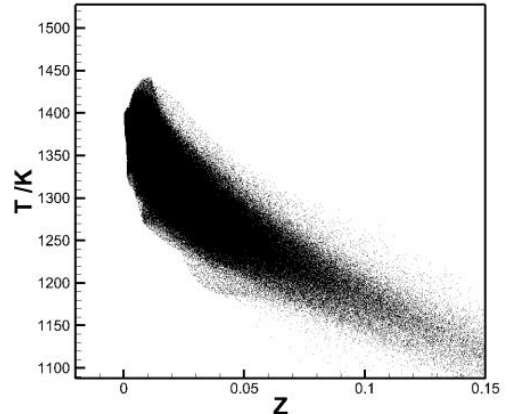

a) $T$ against mixture fraction

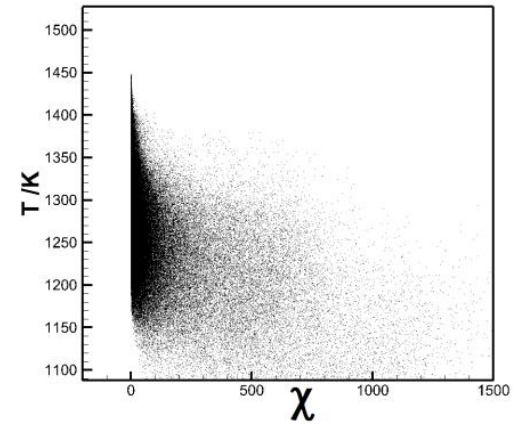

b) $T$ against the scalar dissipation rate

Fig. 3 Scatter plots of temperature against mixture fraction (a) and the scalar dissipation rate (b) at $0.27 \mathrm{~ms}$ in $\mathrm{C} 1 \mathrm{case}$, at the beginning of the temperature rising stage.

\subsection{Analysis of the elementary reactions and evaluation of different HRIs}

Figure 4 displays the instantaneous contour plots of the local heat release rate (HR) and corresponding indicators (HRIs) at $0.36 \mathrm{~ms}$ in $\mathrm{C} 1$ case. This time falls into the 'temperature rising' stage and auto-ignition prevails. [OH] here stands for the mass fraction of $\mathrm{OH}$. Comparison between the first two subplots clearly shows that product of [OH] and $\left[\mathrm{CH}_{2} \mathrm{O}\right]$ can be used to characterize the local HR successfully. Fine structures in the local HR graphic are effectively reproduced in $[\mathrm{OH}] \mathrm{x}\left[\mathrm{CH}_{2} \mathrm{O}\right]$ graphic. Figure $4 \mathrm{c}$ shows that many fine structures of the local $\mathrm{HR}$ are lost when $[\mathrm{OH}] \mathrm{x}[\mathrm{CO}]$ is used as the indicator. It leads to the fact that $[\mathrm{OH}] \times\left[\mathrm{CH}_{2} \mathrm{O}\right]$ performances much better in the $\mathrm{n}$-heptane auto-ignition.

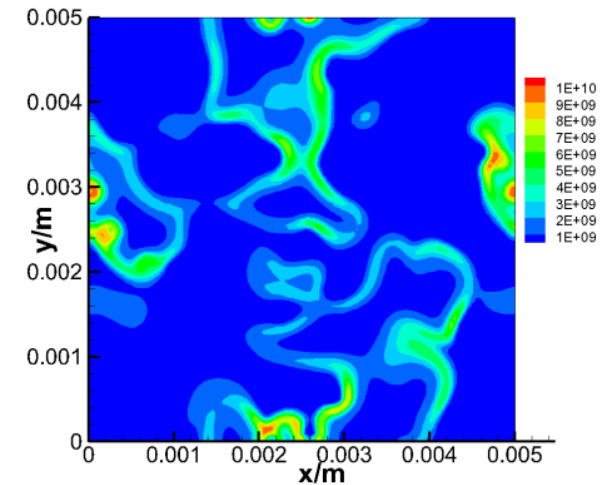

a) the local heat release rate

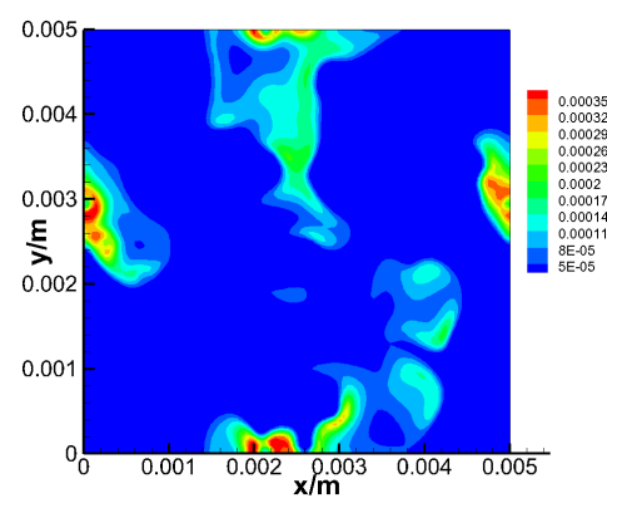

c) $[\mathrm{OH}] \times[\mathrm{CO}]$

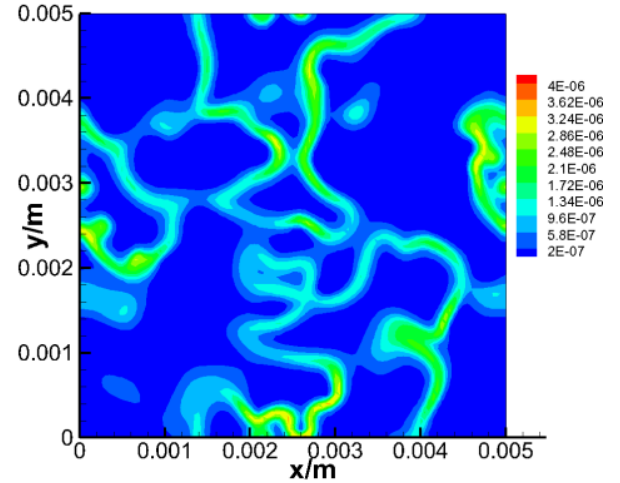

b) $[\mathrm{OH}] \times\left[\mathrm{CH}_{2} \mathrm{O}\right]$

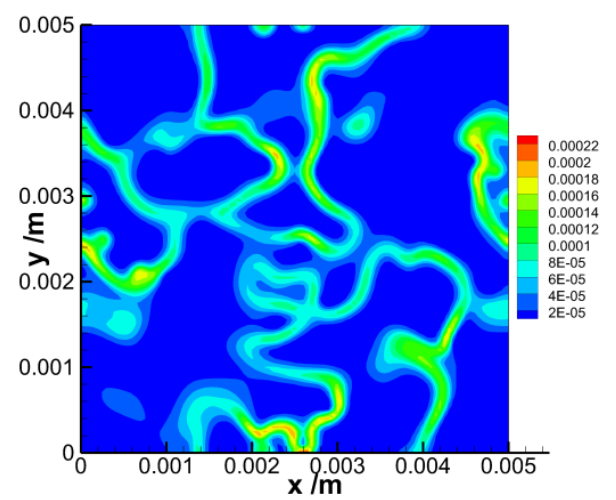

d) $[\mathrm{HCO}]$

Fig. 4 Instantaneous contour plots of local heat release rate (a), product of $[\mathrm{OH}]$ and $\left[\mathrm{CH}_{2} \mathrm{O}\right](b)$, product of $[\mathrm{OH}]$ and $[\mathrm{CO}]$ (c) and $[\mathrm{HCO}](\mathrm{d})$ at $0.36 \mathrm{~ms}$.

Figure $4 \mathrm{~d}$ gives the contour plot of [HCO] which indicates that the distribution also agrees well with the local HR. Analysis of the contour plots of the 44 species shows that only [HCO] and [HCCO] have such similar distribution with the local HR. Figure 5 gives the contour plots of some representative species, while other species like [HCCO] are not 
displayed for simplicity. It is obvious that $[\mathrm{OH}]$ alone is not suitable to be applied as a $\mathrm{HRI}$ and it is the same for [CH] which is not displayed. The drawback of [HCO] as a HRI is that its mass fraction is too small and the signal to noise ratio is low. In the high heat release region, the major species and the corresponding mass fractions are list in Table 2. Here, 'major' means that the mass fraction of one species is larger than $1.0 \times 10^{-3}$. The high heat release region refers to the region where the actual local HR is larger than $1.0 \times 10^{9} \mathrm{~J} /\left(\mathrm{m}^{3} \mathrm{~s}\right)$. The $\mathrm{N}_{2}$ is not involved to the chemical reacting mechanism and then only 9 species are found as the major species. $\mathrm{OH}, \mathrm{CO}$ and $\mathrm{CH}_{2} \mathrm{O}$ are all major species. On the other hand, the mass fractions of HCO and HCCO are $6.3 \times 10^{-5}$ and $4.5 \times 10^{-5}$ which are much smaller. This leads to the fact that $[\mathrm{HCO}]$ is hard to be measured accurately in experiment and larger measurement error may be obtained. The heat release rate indicators $[\mathrm{OH}] \times\left[\mathrm{CH}_{2} \mathrm{O}\right]$ and $[\mathrm{OH}] \times[\mathrm{CO}]$ can be classified to the multiple-kind indicators. In the experiments, the measurement of this kind of indicator requires two species measured accurately. Each of the measurement induces some error and the overall error may also be large. This drawback would not appear in the single species indicator. In this sense, both of the performance of the multiple-kind species $[\mathrm{OH}] \mathrm{x}\left[\mathrm{CH}_{2} \mathrm{O}\right]$ and the representative single species indicator $[\mathrm{HCO}]$ are shown and compared in the following section.

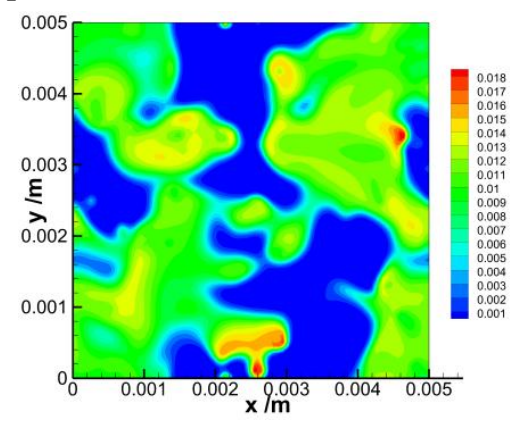

a) $\left[\mathrm{C}_{2} \mathrm{H}_{4}\right]$

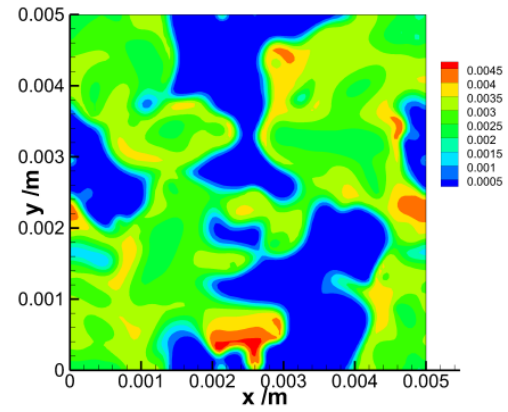

b) $\left[\mathrm{CH}_{2} \mathrm{O}\right]$

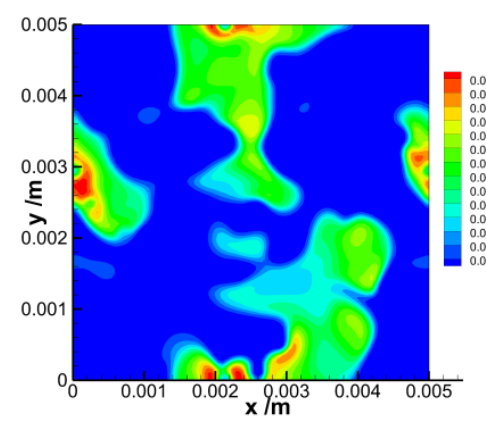

c) $[\mathrm{OH}]$

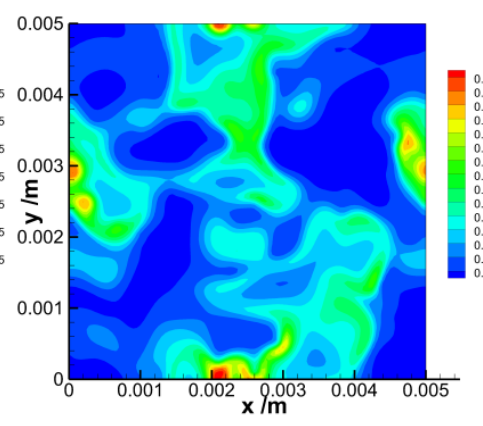

d) $[\mathrm{CO}]$

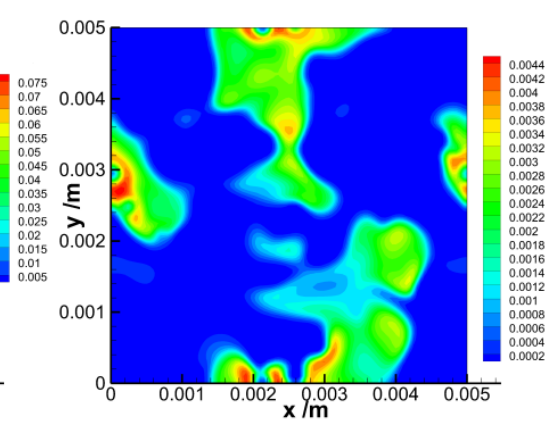

e) $[\mathrm{O}]$

Fig. 5 Instantaneous contour plots of some species, $\left[\mathrm{C}_{2} \mathrm{H}_{4}\right](\mathrm{a}),\left[\mathrm{CH}_{2} \mathrm{O}\right](\mathrm{b}),[\mathrm{OH}](\mathrm{c}),[\mathrm{CO}](\mathrm{d})$ and $[\mathrm{O}](\mathrm{e})$ at $0.36 \mathrm{~ms}$ in $\mathrm{C} 1$ case. The selected plane is the same as that in Fig.4.

Table 2 Mass fractions of the major species larger than $1.0 \times 10^{-3}$

\begin{tabular}{l|l}
\hline \hline Species & Mass fractions \\
\hline $\mathrm{N}_{2}$ & $7.926 \times 10^{-1}$ \\
\hline $\mathrm{O}_{2}$ & $1.047 \times 10^{-1}$ \\
\hline $\mathrm{OH}$ & $2.546 \times 10^{-3}$ \\
\hline $\mathrm{O}$ & $1.490 \times 10^{-3}$ \\
\hline $\mathrm{H}_{2} \mathrm{O}$ & $1.225 \times 10^{-1}$ \\
\hline $\mathrm{CO}$ & $2.749 \times 10^{-2}$ \\
\hline $\mathrm{CO}$ & $1.089 \times 10^{-2}$ \\
\hline $\mathrm{C}_{2} \mathrm{H}_{4}$ & $2.671 \times 10^{-3}$ \\
\hline $\mathrm{CH}_{2} \mathrm{O}$ & $1.093 \times 10^{-3}$ \\
\hline $\mathrm{C}_{3} \mathrm{H}_{4}$ & $1.390 \times 10^{-3}$ \\
\hline
\end{tabular}

The mechanism which makes $[\mathrm{OH}] x\left[\mathrm{CH}_{2} \mathrm{O}\right]$ a good HRI in the two-phase auto-ignition is discussed. Considering that $[\mathrm{HCO}]$ distribution is similar to the local $\mathrm{HR}$ while itself is hard to be measured, the elementary reactions 
responsible for the HCO production are emphasized (Najm et al. 1998; Paul and Najm 1998). In these studies, the reaction $\mathrm{CH}_{2} \mathrm{O}+\mathrm{OH}<=>\mathrm{HCO}+\mathrm{H}_{2} \mathrm{O}$ is found playing an important role in the $\mathrm{HCO}$ production. $[\mathrm{OH}] \times\left[\mathrm{CH}_{2} \mathrm{O}\right]$ is proportional to rate of this elementary reaction and is regarded as able to estimate [HCO]. In present work, this mechanism is evaluated. The contribution of elementary reactions responsible for the HCO production are calculated. The instantaneous data in the high heat release region at $0.36 \mathrm{~ms}$ in $\mathrm{C} 1$ case is set as the sample. Results show that the reaction $\mathrm{CH}_{2} \mathrm{O}+\mathrm{OH}<=>\mathrm{HCO}+\mathrm{H}_{2} \mathrm{O}$ accounts for $35.6 \% \mathrm{HCO}$ production while the reaction $\mathrm{C}_{2} \mathrm{H}_{3}+\mathrm{O}_{2}=>\mathrm{CH}_{2} \mathrm{O}+\mathrm{HCO} 29.6 \%$. The contribution of the rest of the reactions are small. The second reaction also effects the HCO production much. The results indicate that this mechanism is able to explain the performance of $\left.[\mathrm{OH}] \times \mathrm{CH}_{2} \mathrm{O}\right]$ to some extent. In order to make the mechanism more clear, the contributions of elementary reactions to the heat release rate and the characteristics of the distribution of each species are analyzed.

Table 3 lists the top 12 elementary reactions in the rank of the heat release proportion. In this table, the negative value of the heat release proportion indicates that the elementary reaction absorb some heat in this combustion field at this moment. Most of the elementary reactions are the reversible reactions. Other elementary reactions not list in this table release much less heat. In the table, $\mathrm{M}$ stands for the third-body in the system. It is obvious to find that $\mathrm{OH}_{1} \mathrm{CH}_{2} \mathrm{O}$ and HCO are all key species involved into many elementary reactions. In addition, note that the reactants of R5 reaction are closely related to the indicator $[\mathrm{OH}] \mathrm{x}[\mathrm{CO}]$; the reactants of $\mathrm{R} 6$ reaction are closely related to the indicator $[\mathrm{OH}] \times\left[\mathrm{CH}_{2} \mathrm{O}\right]$; the reactant of $\mathrm{R} 4$ reaction is $\mathrm{HCO}$. This prompts that the good HRI is related to one elementary reaction with large heat release proportion. According to this finding, the reactants on one side of the 12 elementary reaction equations can be applied to compose new multiple-kind HRIs. In this way, a series of new multiple-kind HRI are proposed and the corresponding instantaneous contours are checked with the local HR in Fig.4a. Results show that many new HRIs show the similar distributions with Fig.4a, such as $\left.[\mathrm{O}] \times \mathrm{CH}_{3}\right],[\mathrm{H}] \mathrm{x}\left[\mathrm{CH}_{2} \mathrm{O}\right]$ and $\left[\mathrm{C}_{2} \mathrm{H}_{3}\right] \mathrm{x}\left[\mathrm{O}_{2}\right]$. The $\mathrm{HRI}$ $[\mathrm{H}] \mathrm{x}\left[\mathrm{CH}_{2} \mathrm{O}\right]$ is experimentally studied in the laminar premixed flames under various equivalence ratios in (Mulla et al. 2016) and the advantage of the $\mathrm{OH}$-based technique is emphasized. The present results here prove that the mechanism of making $[\mathrm{OH}] \times\left[\mathrm{CH}_{2} \mathrm{O}\right]$ and the new indicators good HRIs is partly due to the corresponding elementary reaction with large heat release proportion. However, all these new HRIs have one common drawback that one species in the HRI definition has a very small mass fraction, such as $\mathrm{CH}_{3}$ and $\mathrm{C}_{2} \mathrm{H}_{3}$ (around $5.0 \times 10^{-5}$ ). In this situation, only the HRIs $[\mathrm{OH}] \times\left[\mathrm{CH}_{2} \mathrm{O}\right]$ and $[\mathrm{OH}] \times[\mathrm{CO}]$ satisfy the two conditions: related to an elementary reaction with large heat release proportion and both the species in the definition have a large mass fraction. This result demonstrates the advantages of $[\mathrm{OH}] \times\left[\mathrm{CH}_{2} \mathrm{O}\right]$ and $[\mathrm{OH}] \mathrm{x}[\mathrm{CO}]$ as an indicator. The R6 reaction is also re-examined and studied in the methane-air and multi component fuel-air mixture based on the elementary reactions analysis in (Nikolaou et al. 2014) and the performance in the multi component fuel flame is emphasized.

Table 3 Important elementary reactions and the corresponding heat release proportion

\begin{tabular}{l|c|c}
\hline \hline Rank & Proportion/\% & Elementary reactions \\
\hline R1 & 22.4 & $\mathrm{C}_{2} \mathrm{H}_{3}+\mathrm{O}_{2}=>\mathrm{CH}_{2} \mathrm{O}+\mathrm{HCO}$ \\
\hline R2 & -13.9 & $\mathrm{O}_{2}+\mathrm{H}<=>\mathrm{OH}+\mathrm{O}$ \\
\hline R3 & 13.4 & $\mathrm{TXCH}_{2}+\mathrm{O}_{2}<=>\mathrm{CO}_{2}+\mathrm{H}_{2}$ \\
\hline R4 & -10.7 & $\mathrm{HCO}+\mathrm{M}<=>\mathrm{CO}+\mathrm{H}+\mathrm{M}$ \\
\hline R5 & 10.0 & $\mathrm{CO}+\mathrm{OH}<=>\mathrm{CO}_{2}+\mathrm{H}$ \\
\hline R6 & 9.2 & $\mathrm{CH}_{2} \mathrm{O}+\mathrm{OH}<=>\mathrm{HCO}_{2} \mathrm{O}$ \\
\hline R7 & 8.4 & $\mathrm{H}_{2} \mathrm{O}+\mathrm{M}<=>\mathrm{H}_{2} \mathrm{O}+\mathrm{M}$ \\
\hline R8 & 8.0 & $\mathrm{HO}_{2}+\mathrm{OH}<=>\mathrm{H}_{2} \mathrm{O}+\mathrm{O}_{2}$ \\
\hline R9 & 6.9 & $\mathrm{CH}_{3}+\mathrm{O}<=>\mathrm{CH}_{2} \mathrm{O}+\mathrm{H}$ \\
\hline R10 & 6.7 & $\mathrm{HO}_{2}+\mathrm{H}<=>2 \mathrm{OH}$ \\
\hline R11 & 5.2 & $\mathrm{H}_{2}+\mathrm{OH}<=>\mathrm{H}_{2} \mathrm{O}+\mathrm{H}$ \\
\hline R12 & 4.9 & $\mathrm{C}_{2} \mathrm{H}_{2}+\mathrm{O}_{2}<=>C \mathrm{CH}_{2} \mathrm{O}+\mathrm{HCO}$ \\
\hline
\end{tabular}

Inspired by the above idea, the study also proposes new multiple-kind HRIs based on the major species mentioned in Table 2. In this situation, two species in Table 2 (except $\mathrm{N}_{2}$ ) are selected discretionarily to compose a new HRI. And all the new HRIs are test through the comparison of the HRI contour with the local HR contour in Fig.4a. Results show that some new ones are able to give the similar distribution and are all list in Table 4. Analysis of the definitions of 
these new HRIs is combined with Fig.5. What displayed in Fig.5 is the contour plots of the major species related to the new HRIs definitions in Table 4. In Fig.5, the plots in the top row are similar to each other and those in the bottom row are similar to each other. Meanwhile, note that one plot in the top row is almost complementary to the plot in the down stream and the boundary of the block regions in these plots are consistent with the high heat release region. The new HRIs in Table 4 can be achieved in this way: select one species appeared in the top row of Fig.5 and then select one from the bottom row, the production of these two species mass fractions can be defined as a HRI. Since the instantaneous contour comparison with the local HR indicates that these new HRIs perform well, one can deduce that the mechanism making $[\mathrm{OH}] \mathrm{x}\left[\mathrm{CH}_{2} \mathrm{O}\right]$ a good $\mathrm{HRI}$ is also closely related to the complementary distribution of $\mathrm{OH}$ and $\mathrm{CH}_{2} \mathrm{O}$. The high $[\mathrm{OH}]$ region and the high $\left[\mathrm{CH}_{2} \mathrm{O}\right]$ region are just separated by the high heat release region. This characteristics of the distribution is believed to be caused by the reacting mechanism of hydrocarbon fuels and the hydrodynamics. $\mathrm{OH}$ often appears in the ignition kernel before the flame front while $\mathrm{CH}_{2} \mathrm{O}$ almost not. And after the flame front, the situation is just the opposite. This has been observed and described in reference (Prasad et al. 2013). The comparison of the various HRIs is shown in the next section.

Table 4 Definitions of the various HRIs and the corresponding $R^{2}$ values

\begin{tabular}{l|l|c}
\hline Number & The indicators & $R^{2}$ \\
\hline HRI-1 & {$[\mathrm{OH}] \mathrm{x}\left[\mathrm{CH}_{2} \mathrm{O}\right]$} & 0.842 \\
\hline HRI-2 & {$[\mathrm{OH}] \mathrm{x}[\mathrm{CO}]$} & 0.377 \\
\hline HRI-3 & {$[\mathrm{OH}] \mathrm{x}\left[\mathrm{C}_{2} \mathrm{H}_{4}\right]$} & 0.693 \\
\hline HRI-4 & {$[\mathrm{O}] \mathrm{x}\left[\mathrm{C}_{2} \mathrm{H}_{4}\right]$} & 0.701 \\
\hline HRI-5 & {$[\mathrm{O}] \mathrm{x}\left[\mathrm{CH}_{2} \mathrm{O}\right]$} & 0.840 \\
\hline HRI-6 & {$[\mathrm{CO}] \mathrm{x}\left[\mathrm{CH}_{2} \mathrm{O}\right]$} & 0.113 \\
\hline HRI-7 & {$[\mathrm{HCO}]$} & 0.662 \\
\hline
\end{tabular}

The comparison of the new proposed HRIs in Table 4 and all the 112 elementary reactions shows that HRI-3 and HRI-5 are related to the two elementary reactions:

$$
\begin{array}{lr}
\mathrm{N} 1: & \mathrm{OH}+\mathrm{C}_{2} \mathrm{H}_{4}<=>\mathrm{C}_{2} \mathrm{H}_{3}+\mathrm{H}_{2} \mathrm{O}, \\
\mathrm{N} 2: & \mathrm{O}+\mathrm{CH}_{2} \mathrm{O}<=>\mathrm{HCO}+\mathrm{OH} .
\end{array}
$$

Not to mention that HRI-1 and HRI-2 are related to reactions R6 and R5. Figure 6 shows the instantaneous contour plots of the local heat release rate from the elementary reactions R5, R6, N1 and N2. Note that each subplot in this figure has the own legend and the magnitude of the local heat release rate in two subplots may be very different. In this sense, this figure just focuses on the shape of the heat release rate distribution. The similarity of Fig.6a and Fig.4c, Fig.6b and Fig.4b indicates the important role of the elementary reaction on the HRI. Although the heat release proportions of elementary reactions $\mathrm{N} 1$ and N2 are not that large (around $2.9 \%$ and $0.9 \%$ ), the corresponding HRI performs well. This emphasizes the importance of the complementary distribution.

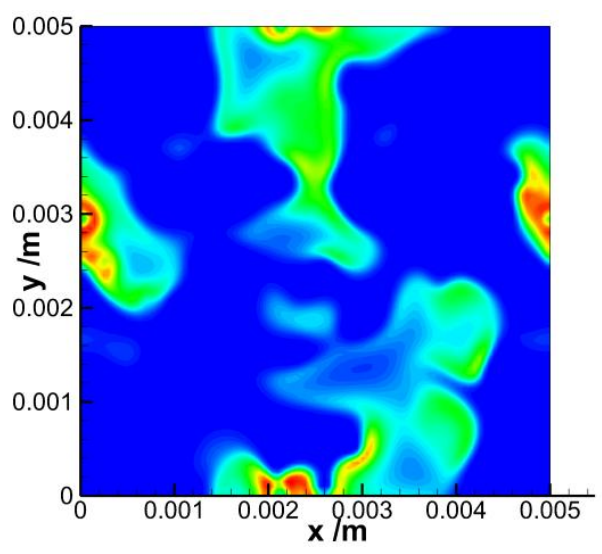

a) R5

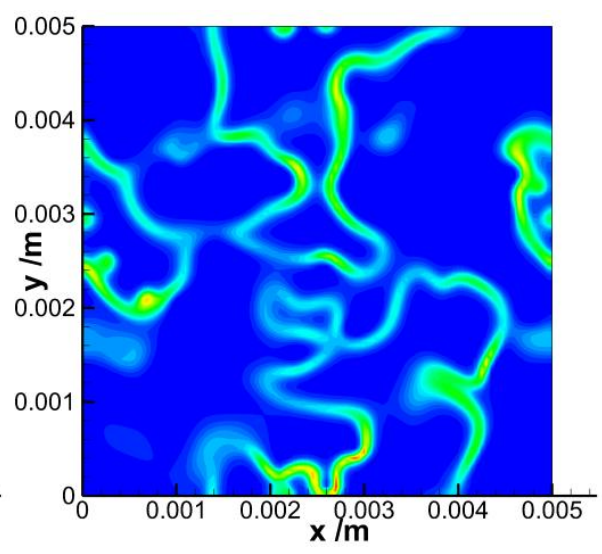

b) R6 


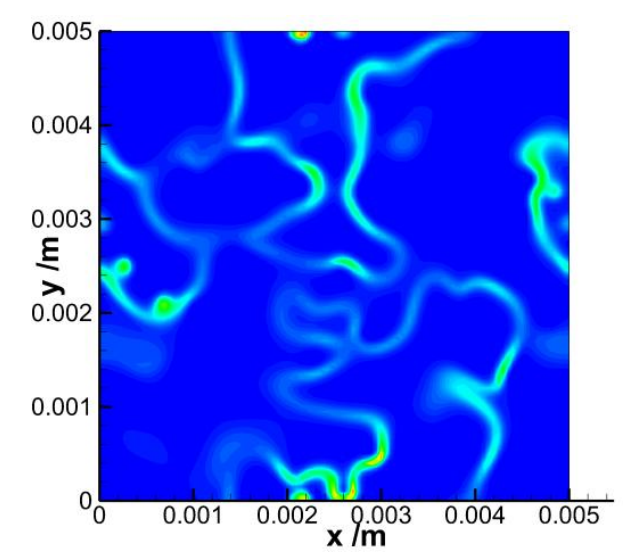

c) $\mathrm{N} 1$

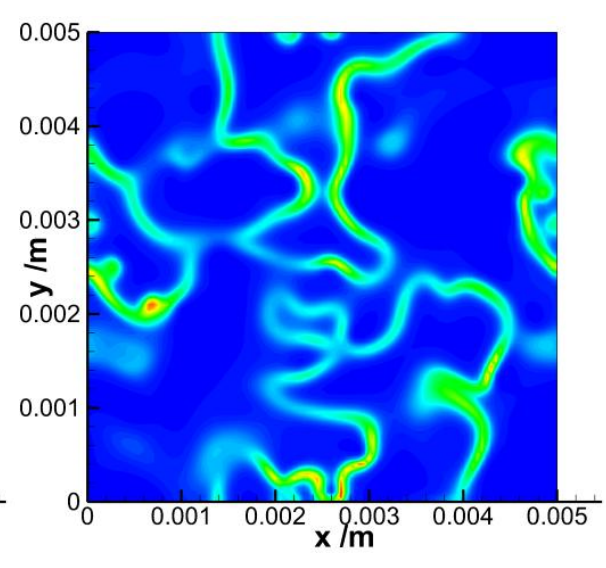

b) $\mathrm{N} 2$

Fig. 6 Instantaneous contour plots of the heat release rate from the elementary reactions R5 (a), R6 (b), N1 (c) and N2 (d).

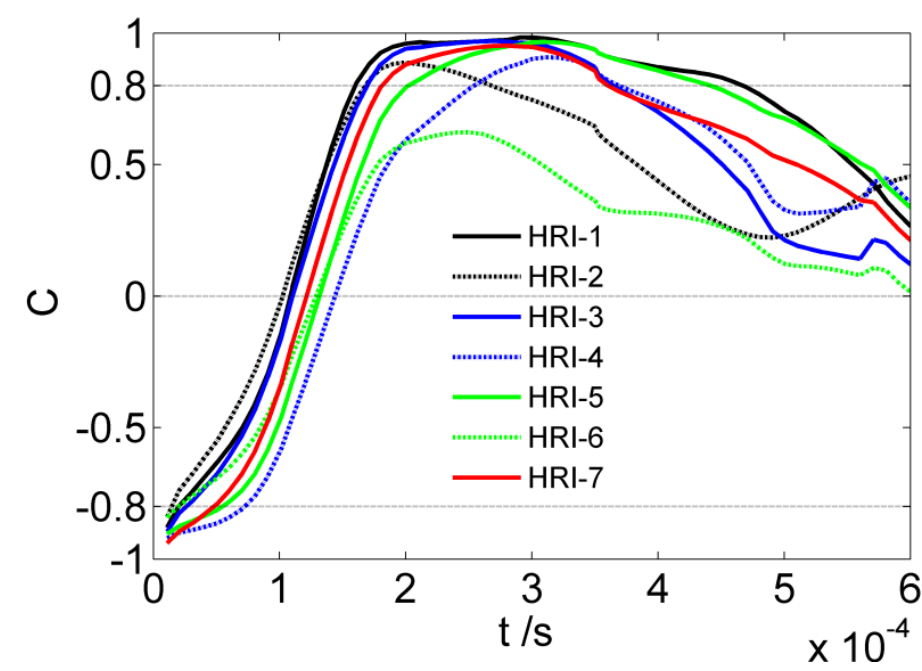

Fig. 7 Linear correlation coefficients based on the seven HRI and the actual local HR against time in $\mathrm{C} 1$ case.

To evaluate the validity of the various HRIs, the coefficient of determination $\left(R^{2}\right)$ is firstly induced. The $R^{2}$ presents the goodness of fit between the observed values and the modeled one. The $\mathrm{R}^{2}$ value is not larger than 1.0. The better the modeled values fit the actual values, the closer of the $\mathrm{R}^{2}$ value to 1 . Table 4 shows the $\mathrm{R}^{2}$ values for various HRIs based on the instantaneous data at $0.36 \mathrm{~ms}$ in $\mathrm{C} 1$ case. Obviously $[\mathrm{OH}] \mathrm{x}\left[\mathrm{CH}_{2} \mathrm{O}\right]$ perform the best between the seven ones. $[\mathrm{O}] \mathrm{x}\left[\mathrm{CH}_{2} \mathrm{O}\right],[\mathrm{O}] \mathrm{x}\left[\mathrm{C}_{2} \mathrm{H}_{4}\right]$ and $[\mathrm{OH}] \times\left[\mathrm{C}_{2} \mathrm{H}_{4}\right](\mathrm{HRI}-5, \mathrm{HRI}-4$ and HRI-3) follow behind. [HCO] also performs not bad. To evaluate the performance of HRIs at the whole temperature rising stage, the correlation coefficients (C) between the indicators and the actual local HR are present. Fig. 2c and Fig. 2d shows the evolution of two correlation coefficients: correlation coefficient between $[\mathrm{OH}] \mathrm{x}\left[\mathrm{CH}_{2} \mathrm{O}\right]$ and the local $\mathrm{HR}$, correlation coefficient between $[\mathrm{OH}] \mathrm{x}[\mathrm{CO}]$ and the local HR. In present study, correlation coefficient in the range of $[-1.0,-0.8]$ and $[0.8,1.0]$ is regarded as the marker of strong linear relationship. The correlation coefficient is not close to 1 before auto-ignition occurs and there exists a change of the sign at this early stage. At about $0.16 \mathrm{~ms}$ in $\mathrm{C} 1$ case (or $0.11 \mathrm{~ms}$ in $\mathrm{C} 2$ case), both two correlation coefficients become larger than 0.8 . From $0.16 \mathrm{~ms}$ to $0.45 \mathrm{~ms},[\mathrm{OH}] \mathrm{x}\left[\mathrm{CH}_{2} \mathrm{O}\right]$ and the local HR's correlation coefficient remains larger than 0.8 in $\mathrm{C} 1$ case. In $\mathrm{C} 2$ case, the corresponding time region is $0.11 \mathrm{~ms} \sim 0.37 \mathrm{~ms}$. $[\mathrm{OH}] \mathrm{x}\left[\mathrm{CH}_{2} \mathrm{O}\right]$ is verified to be a very effective indicator of the local HR. After $\mathrm{t}=0.45 \mathrm{~ms}$, the flame is fully developed and the linear relationship becomes relatively poor. Test of the correlation coefficients is then extended to the new HRIs. Figure 7 shows the correlation coefficients based on the seven HRI and the local HR against time in $\mathrm{C} 1$ case. Performance at the whole temperature rising stage illustrates that $[\mathrm{OH}] \mathrm{x}\left[\mathrm{CH}_{2} \mathrm{O}\right]$ perform the best. Meanwhile, the profiles of $[\mathrm{O}] \mathrm{x}\left[\mathrm{CH} \mathrm{H}_{2} \mathrm{O}\right]$, $[\mathrm{OH}] \times\left[\mathrm{C}_{2} \mathrm{H}_{4}\right]$ and $[\mathrm{HCO}]$ are close to that of $[\mathrm{OH}] \times\left[\mathrm{CH}_{2} \mathrm{O}\right]$. The trend of each profile is similar to each other. The performances are mainly in consistent with conclusion obtained from the $\mathrm{R}^{2}$ values in Table 4: the indicator with higher $\mathrm{R}^{2}$ value shows better profile in Fig.7. The comparison of $[\mathrm{OH}] \times\left[\mathrm{CH}_{2} \mathrm{O}\right]$ and $[\mathrm{HCO}]$ illustrates that the multiple-kind HRI may perform better than the single species HRI theoretically. When the measurement error is taken into 
consideration, this multiple-kind HRI also benefits from the large mass fractions of $\mathrm{OH}$ and $\mathrm{CH}_{2} \mathrm{O}$.

Based on the analysis in this section, one can see that the new multiple-kind HRIs perform well and $[\mathrm{OH}] \times\left[\mathrm{CH}_{2} \mathrm{O}\right]$ remains the best one at the whole temperature rising stage. This also proves that the mechanism making $[\mathrm{OH}] \mathrm{x}\left[\mathrm{CH}_{2} \mathrm{O}\right]$ a good HRI is closely related to the complementary distribution of $\mathrm{OH}$ and $\mathrm{CH}_{2} \mathrm{O}$. Meanwhile, the large heat release proportion and the $\mathrm{HCO}$ production of the reaction $\mathrm{CH}_{2} \mathrm{O}+\mathrm{OH}<=>\mathrm{HCO}+\mathrm{H}_{2} \mathrm{O}$ helps the indicator $[\mathrm{OH}] \times\left[\mathrm{CH}_{2} \mathrm{O}\right]$ to be a best one. Limited by the small mass fraction of the composing species, many new multiple-kind HRIs is hard to be applied while $[\mathrm{O}] \mathrm{x}\left[\mathrm{CH}_{2} \mathrm{O}\right],[\mathrm{O}] \mathrm{x}\left[\mathrm{C}_{2} \mathrm{H}_{4}\right]$ and $[\mathrm{OH}] \mathrm{x}\left[\mathrm{C}_{2} \mathrm{H}_{4}\right]$ provide new choices of the definitions of HRI.

\subsection{Quantitative relations between HRIs and HR}

Note that the high correlation coefficients in Fig.2 and Fig.7 indicate a clear quantitative relationship between the HRIs and the local HR which is analyzed in this section. And the focus is put on the $\left.\mathrm{HRI}[\mathrm{OH}] \times \mathrm{CH}_{2} \mathrm{O}\right]$ since it has shown the great advantage. Performance of the $[\mathrm{OH}] \mathrm{x}[\mathrm{CO}]$ is also analyzed for comparison and the sample data are all taken from the $\mathrm{C} 1$ case.

Performances of these two HRIs in the three stages of the auto-ignition process is compared. Figure 8 shows the scatter plots of the two indicators against the local HR. Line fitting of the scatter points is also displayed in each subplot. In this figure, three times $0.12 \mathrm{~ms}, 0.36 \mathrm{~ms}$ and $0.58 \mathrm{~ms}$ are selected which each falls into three stages. It is obvious that the relationship between the indicator and the local HR is not clear at $0.12 \mathrm{~ms}$. Figure 8a shows that the scatter points can be roughly divided into two branches: one branch with negative HR and negligible species mass fractions, the other with positive HR and indicator. The global fitting line can not capture the feature of both two branches at the same time. The local HR at present time is about two or three orders smaller in magnitude than that in the 'temperature rising' stage, and in fact it is difficult to measure such small signals in the experiments. In this sense, the disordered relationship at this stage does not influence much. At $0.36 \mathrm{~ms}$, a clear linear relationship between $[\mathrm{OH}] \times\left[\mathrm{CH}_{2} \mathrm{O}\right]$ and the local HR can be seen, and the fitting line passes through the origin point which is to say that the quantitative relationship is in fact a proportional relationship. At this moment, the proportional relationship between $[\mathrm{OH}] \mathrm{x}[\mathrm{CO}]$ and the local HR is roughly satisfied although it is not as good as the other one.

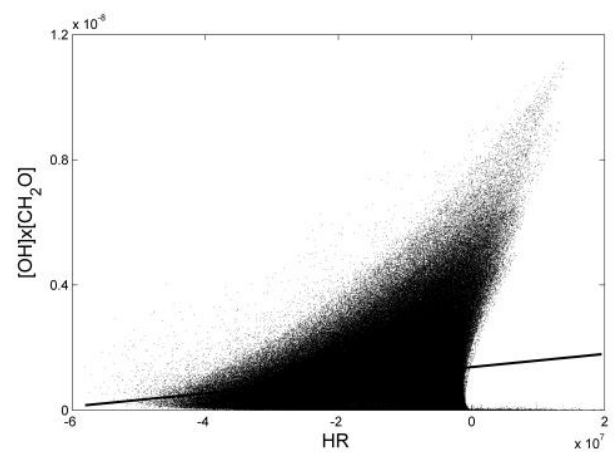

a) $[\mathrm{OH}] \times\left[\mathrm{CH}_{2} \mathrm{O}\right]$ at $0.12 \mathrm{~ms}$

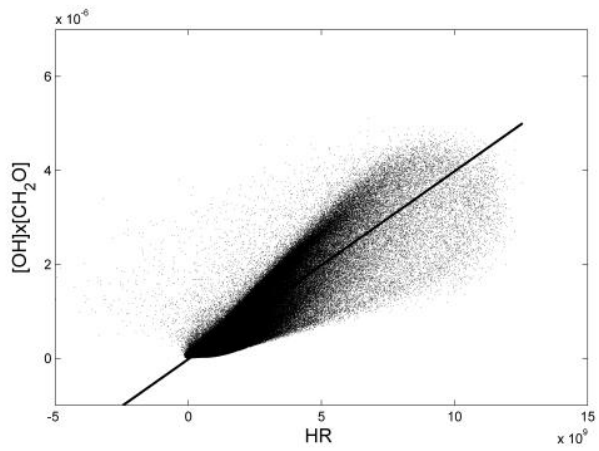

c) $[\mathrm{OH}] \mathrm{x}\left[\mathrm{CH}_{2} \mathrm{O}\right]$ at $0.36 \mathrm{~ms}$

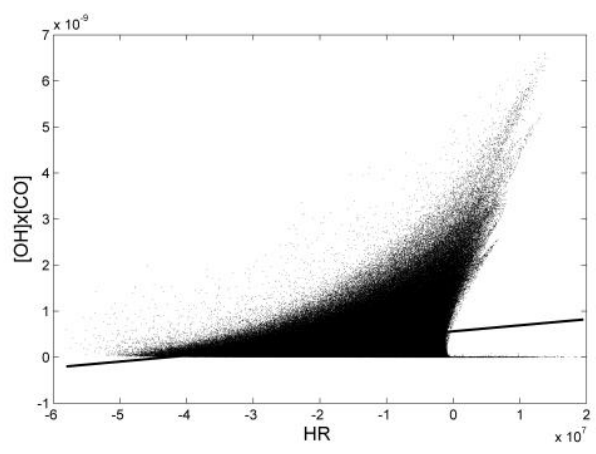

b) $[\mathrm{OH}] \mathrm{x}[\mathrm{CO}]$ at $0.12 \mathrm{~ms}$

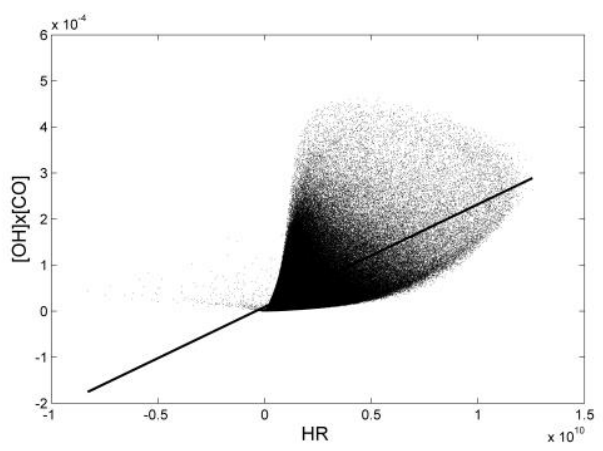

d) $[\mathrm{OH}] \mathrm{x}[\mathrm{CO}]$ at $0.36 \mathrm{~ms}$ 


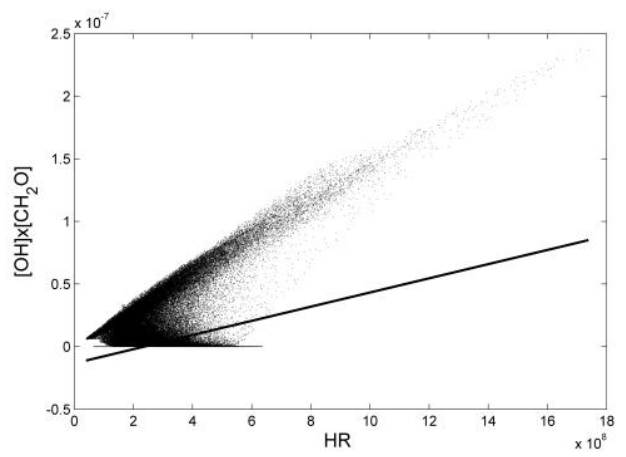

e) $[\mathrm{OH}] \times\left[\mathrm{CH}_{2} \mathrm{O}\right]$ at $0.58 \mathrm{~ms}$

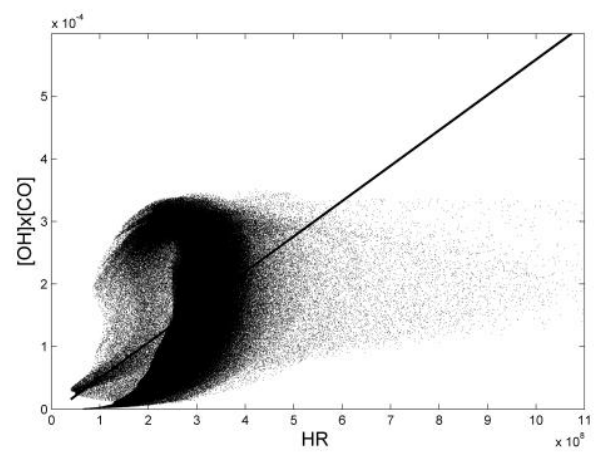

f) $[\mathrm{OH}] x[\mathrm{CO}]$ at $0.58 \mathrm{~ms}$

Fig. 8 Scatter plots of indicators against the local heat release rate at three times and corresponding fitting line.

At $0.58 \mathrm{~ms}$, the shape of the scatter plots shows that the relationship between $[\mathrm{OH}] \mathrm{x}\left[\mathrm{CH}_{2} \mathrm{O}\right]$ and the local $\mathrm{HR}$ can be divided into several branches. At adjacent time, this shape changes much, which states that the simple global linear relationship is not suitable at this time. Briefly speaking, the scatter plots reinforce the conclusion that $[\mathrm{OH}] \mathrm{x}\left[\mathrm{CH}_{2} \mathrm{O}\right]$ is a proper HR indicator at the temperature rising stage, i.e. when auto-ignition occurs. The linear proportional relationship is then clarified. Meanwhile, $[\mathrm{OH}] \mathrm{x}[\mathrm{CO}]$ shows less obvious relationship with the local HR.

To quantitatively study the linear relationship during ignition, Figure 9 shows the comparison of all the fitting lines in the time range of $0.16 \mathrm{~ms} \sim 0.45 \mathrm{~ms}$. The fitting line is in the form of

$$
y=s x+d i s
$$

where $s$ and dis are the slope and intercept, respectively. Fitting lines corresponding to each $0.01 \mathrm{~ms}$ data are drawn as fine solid line in this figure, while the global fitting line in this time range is drawn as the thick solid line. As shown in Fig. 9a all the fitting curves basically pass through the origin point, indicating the validity of the proportional relationship at the whole time range. Note that the change of the slopes of the fitting lines is limited into a small interval. Figure $9 \mathrm{~b}$ shows the fitting lines based on the indicator $[\mathrm{OH}] \mathrm{x}[\mathrm{CO}]$. It is obvious the fitting lines do not pass through the origin point all, which indicates that the relationship based on this indicator is complicated.

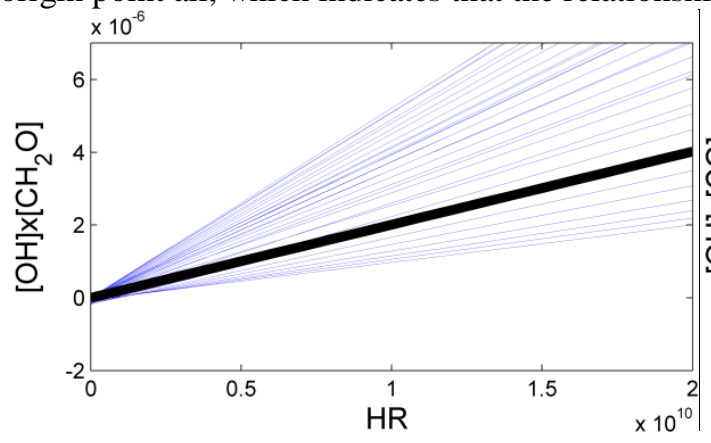

a)

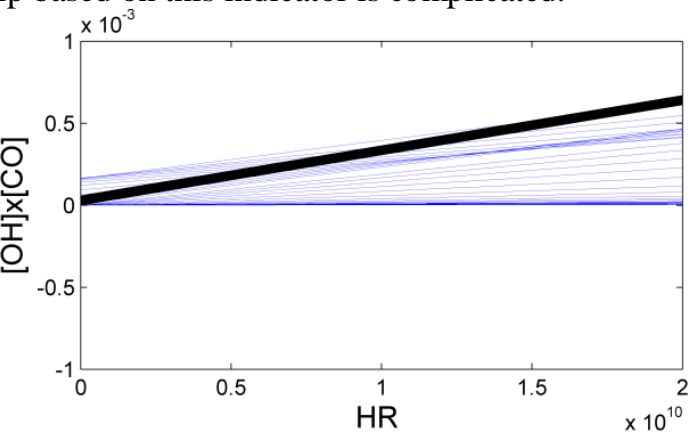

b)

Fig. 9 Linear fitting between the indicators and the HR at $\mathrm{t}=0.16 \mathrm{~ms} \sim 0.45 \mathrm{~ms}$.

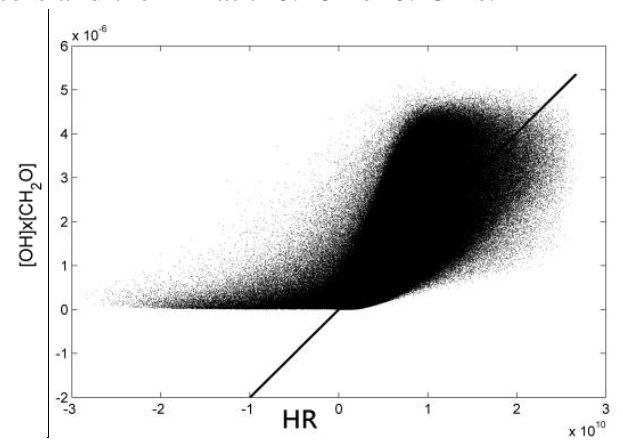

Fig. 10 Scatter plot of all the $[\mathrm{OH}] \mathrm{x}\left[\mathrm{CH}_{2} \mathrm{O}\right]$ against the HR in the range of $0.16 \mathrm{~ms} \sim 0.45 \mathrm{~ms}$. 


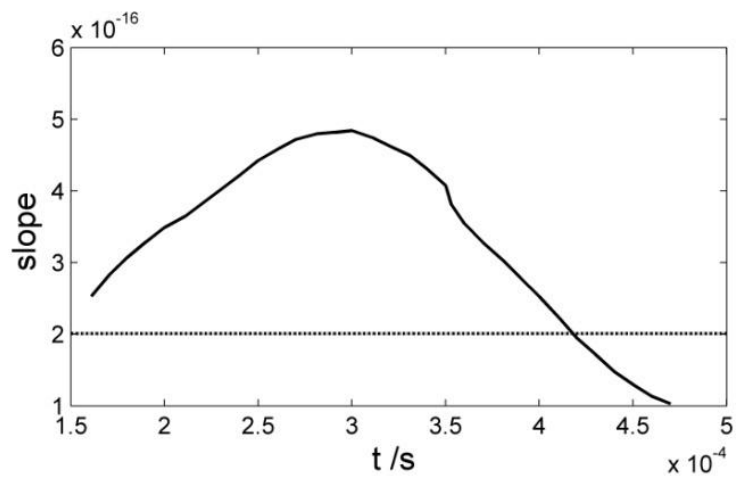

Fig. 11 Evolution of the slopes of the fitting lines against time and the averaged line.

Figure 10 shows all the scatter data and corresponding global fitting line in the time range of $0.16 \mathrm{~ms} \sim 0.45 \mathrm{~ms}$. It is obvious that the proportional line is able to describe the main features of the whole temperature rising stage to some extent. In order to describe the change of the slopes of all fitting lines in this period, Figure 11 shows the evolution of the slopes. The dotted line in this figure shows the slope value of the global fitting line. It is visible that the slopes fall into the range $\left[1 \times 10^{-16}, 5 \times 10^{-16}\right]$ while the slope of the global fitting line is approximately $2 \times 10^{-16}$. The linear relationship in $\mathrm{C} 2$ case is also evaluated and it is found that the slopes also fall into the same range at the temperature rising stage. The change of the slope with time is analyzed based on the conditional mean of the indicator $\left([\mathrm{OH}] \times\left[\mathrm{CH}_{2} \mathrm{O}\right] \mid \mathrm{Z}\right)$ and the local $\mathrm{HR}(\mathrm{HR} \mid \mathrm{Z})$. The profiles of $[\mathrm{OH}] \mathrm{x}\left[\mathrm{CH}_{2} \mathrm{O}\right] \mid \mathrm{Z}$ against $\mathrm{HR} \mid \mathrm{Z}$ at $\mathrm{t}>0.34 \mathrm{~ms}$ in $\mathrm{C} 1 \mathrm{case}$ indicate the existence of one turning point of $Z\left(Z_{\text {turn }}\right)$. The profile at $Z>Z_{\text {turn }}$ is a good linear profile while beyond the linear profile at $Z<Z_{\text {turn. }}$. This complex profile is believed to be related to the local equivalence ratio and contributes to the change of the slope. This is to be analyzed in the future work.

In order to study the turbulence effect on the indicators, Figure 12 gives the $\mathrm{R}^{2}$ profiles against the scalar dissipation rate $\chi$ at $0.27 \mathrm{~ms}$ and $0.36 \mathrm{~ms}$ in $\mathrm{C} 1$ case. The $\mathrm{R}^{2}$ values are calculated based on the $[\mathrm{OH}] \mathrm{x}\left[\mathrm{CH}_{2} \mathrm{O}\right] \mathrm{data}$ and the local HR conditioned on the specific $\chi$. The scalar dissipation rate of the mixture fraction is strongly affected by the strain rate and the turbulent intensity. In the flamelet models, the scalar dissipation rate can represent the turbulent effect on the laminar flames to some extent. In this sense, the performance of the indicators against $\chi$ is able to reflect the turbulent effect. In Fig.12, the $\mathrm{R}^{2}$ values under various $\chi$ are all close to 1 and the change with $\chi$ is small, which indicates that the indicator may perform well under various turbulent intensities. The direct way to study the dependency of the indicators on the turbulence is to simulate a series of cases with different turbulent intensity, which is the aim of the future work.

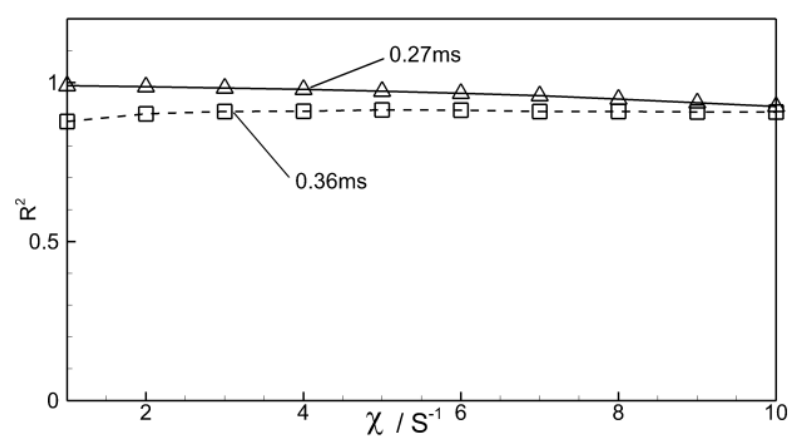

Fig. 12 The $\mathrm{R}^{2}$ profiles against the scalar dissipation rate at $0.27 \mathrm{~ms}$ and $0.36 \mathrm{~ms}$ in $\mathrm{C} 1$ case.

\subsection{Heat release associated with different combustion regimes}

To clarify the effect of the combustion regimes, the flame index FI is introduced here. The value of the flame index is calculated by multiplying the spatial gradients of the fuel and oxidizer mass fractions as:

$$
F I=\nabla Y_{f} \cdot \nabla Y_{O}
$$


where $Y_{f}$ and $Y o$ are the mass fractions of the fuel and oxidizer respectively. The flame index is often applied to distinguish the premixed and non-premixed flame regimes, indicated by the positive and negative values. Baba and Kurose (2008), Fujita et al. (2013), and Kitano et al. (2013) adopted this flame index to study the combustion of the liquid fuel and illustrated the relative contribution of different combustion regimes.

Figure 13 displays the contour plot of the local HR and the $F I=0$ isoline. In this figure many block areas exist and the inside parts are corresponding to the non-premixed flames while outside the premixed flames. It is obvious that high HR values basically locate in the premixed flames regions. Heat release is very intense in the premixed regions. This states that the premixed flames play an important role in the early stage of the auto-ignition of liquid fuel, which is consistent with the study of Luo et al. (2011).

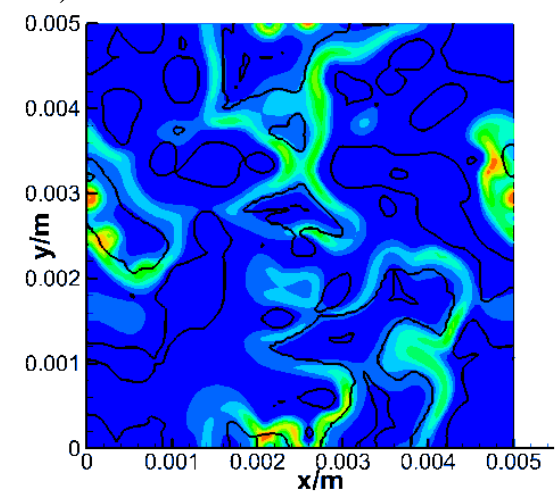

Fig. 13 Instantaneous contour plot of the local HR and the isoline of $F I=0$ at $0.36 \mathrm{~ms}$ in $\mathrm{C} 1$ case.

To evaluate the indicator in different combustion regimes, Figure 14 shows the scatter plots of the unconditional and conditional $[\mathrm{OH}] \times\left[\mathrm{CH}_{2} \mathrm{O}\right]$ against the local $\mathrm{HR}$ and corresponding fitting line at $0.36 \mathrm{~ms}$ in $\mathrm{C} 1$ case. Figure $14 \mathrm{~b}$ shows the data conditioned on premixed flame regions while Fig. 14c gives that on non-premixed flame regions. As shown in Fig. 13, Fig. 14b and 14c, the value of the local HR is higher in the premixed flame regions. At the same time, all three fitting lines pass through the origin point and the proportional relationship is basically satisfied. Detail information of these fitting lines can be found in Table 5. It is easy to find that the premixed flame regions perform more like the whole flame field. All three correlation coefficients are larger than 0.8 , indicating the validity of the emphasized proportional relationship.

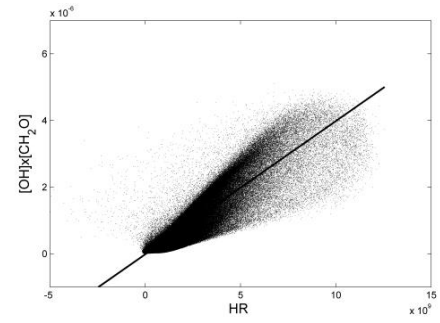

a)

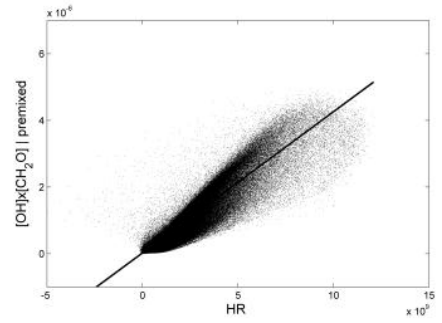

b)

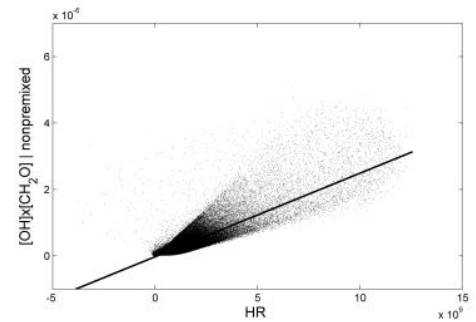

c)

Fig. 14. Scatter plots of the $[\mathrm{OH}] \times\left[\mathrm{CH}_{2} \mathrm{O}\right]$ indicator and the conditional indicator against the heat release rate at $\mathrm{t}=0.36 \mathrm{~ms}$. The unconditional indicator is shown in plot (a), while indicator conditioned on premixed flame region and non-premixed flame region are shown in plots (b) and (c).

Table 5 Parameters of the line expressions under different conditions.

\begin{tabular}{l|c|c}
\hline Condition on & Slope & Correlation \\
\hline All data & $4.000 \times 10^{-16}$ & 0.9177 \\
\hline Premixed data & $4.239 \times 10^{-16}$ & 0.9420 \\
\hline Non-premixed data & $2.516 \times 10^{-16}$ & 0.8647 \\
\hline
\end{tabular}

\section{Conclusions}

This paper explores the heat release indicators, which is quite useful in experimental research, with the direct numerical simulation. The auto-ignition of liquid n-heptane droplets is calculated with a detailed reacting mechanism. The species transport equations are all directly solved so that the local heat release rate and mass fractions of the key 
species can be obtained. The elementary reactions involved are examined to describe the features of a good HRI, which helps to find HRI for other different cases. The main conclusions are:

1) The formerly reported HRI for methane flames, $[\mathrm{OH}] \mathrm{x}\left[\mathrm{CH}_{2} \mathrm{O}\right]$, is also a proper heat release rate for the auto-ignition n-heptane droplets. The fine structures of contours of heat release rate are reproduced well. The corresponding proportional coefficient is found to be in a limited range around $2.0 \times 10^{-16}$.

2) Analysis of the elementary reactions explains what makes $[\mathrm{OH}] \mathrm{x}\left[\mathrm{CH}_{2} \mathrm{O}\right]$ a good HRI. Its good performance mainly results from the reaction $\mathrm{CH}_{2} \mathrm{O}+\mathrm{OH}<=>\mathrm{HCO}+\mathrm{H}_{2} \mathrm{O}$, which has a large portion of heat release and plays an important role in the $\mathrm{HCO}$ production. And it is also attributed to the large concentrations of each species and the complementary distribution of $\mathrm{OH}$ and $\mathrm{CH}_{2} \mathrm{O}$. These features offers the criteria or guidelines for the HRI selection. Under the guidance of the above analysis, some new HRIs are proposed, which are also proved to have a not bad performance.

3) The proposed proportional relationship is verified in different combustion regimes, i.e. the premixed and non-premixed regions, with a slight different in the quantitative proportional coefficient. The combustion heat is mainly produced in the premixed flame region.

\section{Acknowledgement}

The authors would like to acknowledge the funding of the Programs (Grant No. 50936005 and 51576182) of National Natural Science of China.

\section{References}

Aggarwal, S. K. 1998. A review of spray ignition phenomena: Present status and future research. Progress in Energy and Combustion Science 24 (6):565-600.

Amantini, G., J. H. Frank, B. A. V. Bennett, M. D. Smooke, and A. Gornez. 2007. Comprehensive study of the evolution of an annular edge flame during extinction and reignition of a counterflow diffusion flame perturbed by vortices. Combustion and Flame 150 (4):292-319.

Ayoola, B. O., R. Balachandran, J. H. Frank, E. Mastorakos, and C. F. Kaminski. 2006. Spatially resolved heat release rate measurements in turbulent premixed flames. Combustion and Flame 144 (1-2):1-16.

Baba, Y., and R. Kurose. 2008. Analysis and flamelet modelling for spray combustion. Journal of Fluid Mechanics 612.

Balachandran, R., B. O. Ayoola, C. F. Kaminski, A. P. Dowling, and E. Mastorakos. 2005. Experimental investigation of the nonlinear response of turbulent premixed flames to imposed inlet velocity oscillations. Combustion and Flame 143 (1-2):37-55.

Borghesi, G., E. Mastorakos, and R. S. Cant. 2013. Complex chemistry DNS of n-heptane spray autoignition at high pressure and intermediate temperature conditions. Combustion and Flame 160 (7):1254-1275.

Dworkin, S. B., A. M. Schaffer, B. C. Connelly, M. B. Long, M. D. Smooke, M. A. Puccio, B. McAndrew, and J. H. Miller. 2009. Measurements and calculations of formaldehyde concentrations in a methane/N2/air, non-premixed flame: Implications for heat release rate. Proceedings of the Combustion Institute 32 (1):1311-1318.

Fayoux, A., K. Zähringer, O. Gicquel, and J. C. Rolon. 2005. Experimental and numerical determination of heat release in counterflow premixed laminar flames. Proceedings of the Combustion Institute 30 (1):251-257.

Frank, J. H., S. A. Kaiser, and M. B. Long. 2002. Reaction-rate, mixture-fraction, and temperature imaging in turbulent methane/air jet flames. Proceedings of the Combustion Institute 29:2687-2694.

Fujita, A., H. Watanabe, R. Kurose, and S. Komori. 2013. Two-dimensional direct numerical simulation of spray flames - Part 1: Effects of equivalence ratio, fuel droplet size and radiation, and validity of flamelet model. Fuel 104:515-525.

Gordon, R., A. Masri, and E. Mastorakos. 2009. Heat release rate as represented by $[\mathrm{OH}] \times[\mathrm{CH} 2 \mathrm{O}]$ and its role in autoignition. Combustion Theory and Modelling 13 (4):645-670.

Im, H. G., J. H. Chen, and C. K. Law. 1998. Ignition of hydrogen-air mixing layer in turbulent flows. Symposium (International) on Combustion 27 (1):1047-1056.

Jenny, P., D. Roekaerts, and N. Beishuizen. 2012. Modeling of turbulent dilute spray combustion. Progress in Energy and Combustion Science 38 (6):846-887.

Kathrotia, T., Riedel, U., Warnatz, J., 2009. A numerical study on the relation of $\mathrm{OH}^{*}, \mathrm{CH}^{*}$, and $\mathrm{C}^{*}$ chemiluminescence and heat release in premixed methane flames. 
Kitano, T., Nishio, J., Kurose, R., and Komori, S. 2014. Evaporation and combustion of multicomponent fuel droplet. Fuel 136:219-225.

Kitano, T., Nishio, J., Kurose, R., and Komori, S. 2014. Effect of ambient pressure, gas temperature and combustion reaction on droplet evaporation. Combustion and Flame 161:551-564.

Kitano, T., Nakatani, T., Kurose, R., and Komori, S. 2013. Two-dimensional direct numerical simulation of spray flames - Part 2: Effects of ambient pressure and lift, and validity of flamelet model. Fuel 104:526-535.

Knudsen, E., and H. Pitsch. 2009. A general flamelet transformation useful for distinguishing between premixed and non-premixed modes of combustion. Combustion and Flame 156 (3):678-696.

Liu, S., J. C. Hewson, J. H. Chen, and H. Pitsch. 2004. Effects of strain rate on high-pressure nonpremixed n-heptane autoignition in counterflow. Combustion and Flame 137 (3):320-339.

Luo, K., H. Pitsch, M. G. Pai, and O. Desjardins. 2011. Direct numerical simulations and analysis of three-dimensional n-heptane spray flames in a model swirl combustor. Proceedings of the Combustion Institute 33 (2):2143-2152.

Mastorakos, E. 2009. Ignition of turbulent non-premixed flames. Progress in Energy and Combustion Science 35 (1):57-97.

Miller, R. S., K. Harstad, and J. Bellan. 1998. Evaluation of equilibrium and non-equilibrium evaporation models for many-droplet gas-liquid flow simulations. International Journal of Multiphase Flow 24 (6):1025-1055.

Mittal, V., D. J. Cook, and H. Pitsch. 2012. An extended multi-regime flamelet model for IC engines. Combustion and Flame 159 (8):2767-2776.

Mulla, I.A., Dowlut, A., Hussain, T., Nikolaou, Z.M., Chakravarthy, S.R., Swaminathan, N., Balachandran, R., 2016. Heat release rate estimation in laminar premixed flames using laser-induced fluorescence of $\mathrm{CH} 2 \mathrm{O}$ and $\mathrm{H}$-atom. Combustion and Flame.

Najm, H.N., Paul, P.H., Mueller, C.J., Wyckoff, P.S., 1998. On the Adequacy of Certain Experimental Observables as Measurements of Flame Burning Rate. Combustion and Flame 113: 312-332.

Nikolaou, Z.M., Swaminathan, N., 2014. Heat release rate markers for premixed combustion. Combustion and Flame 161: 3073-3084.

O’Loughlin, W., and A. R. Masri. 2011. A new burner for studying auto-ignition in turbulent dilute sprays. Combustion and Flame 158 (8):1577-1590.

O'Loughlin, W., and A. R. Masri. 2012. The Structure of the Auto-Ignition Region of Turbulent Dilute Methanol Sprays Issuing in a Vitiated Co-flow. Flow, Turbulence and Combustion 89 (1):13-35.

Paul, P. H., and H. N. Najm. 1998. Planar laser-induced fluorescence imaging of flame heat release rate. Symposium (International) on Combustion 27 (1):43-50.

Prasad, V.N., Masri, A.R., Navarro-Martinez, S., Luo, K.H., 2013. Investigation of auto-ignition in turbulent methanol spray flames using Large Eddy Simulation. Combustion and Flame 160: 2941-2954.

Rehm, J. E., and P. H. Paul. 2000. Reaction rate imaging. Proceedings of the Combustion Institute 28:1775-1782.

Reveillon, J., C. Pera, and Z. Bouali. 2011. Examples of the potential of DNS for the understanding of reactive multiphase flows. International Journal of Spray and Combustion Dynamics 3 (1):63-92.

Schroll, P., A. P. Wandel, R. S. Cant, and E. Mastorakos. 2009. Direct numerical simulations of autoignition in turbulent two-phase flows. Proceedings of the Combustion Institute 32 (2):2275-2282.

Wang, H., K. Luo, and J. Fan. 2012. Direct numerical simulation and CMC (conditional moment closure) sub-model validation of spray combustion. Energy 46 (1):606-617.

Wang, H., K. Luo, and J. Fan. 2014. Effects of turbulent intensity and droplet diameter on spray combustion using direct numerical simulation. Fuel 121:311-318.

Wang, Y., and C. Rutland. 2007. Direct numerical simulation of ignition in turbulent $n$-heptane liquid-fuel spray jets. Combustion and Flame 149 (4):353-365.

Wang, Y., and C. J. Rutland. 2005. Effects of temperature and equivalence ratio on the ignition of n-heptane fuel spray in turbulent flow. Proceedings of the Combustion Institute 30 (1):893-900.

Yoo, C. S., R. Sankaran, and J. H. Chen. 2009. Three-dimensional direct numerical simulation of a turbulent lifted hydrogen jet flame in heated coflow: flame stabilization and structure. Journal of Fluid Mechanics 640:453. 